\title{
Spatial- and Task-Dependent Neuronal Responses during Real and Virtual Translocation in the Monkey Hippocampal Formation
}

\author{
Nobuhisa Matsumura, ${ }^{1,2}$ Hisao Nishijo, ${ }^{2}$ Ryoi Tamura, ${ }^{2}$ Satoshi Eifuku, ${ }^{2}$ Shunro Endo, ${ }^{1}$ and Taketoshi Ono ${ }^{2}$ \\ Departments of ${ }^{1}$ Neurosurgery and ${ }^{2}$ Physiology, Faculty of Medicine, Toyama Medical and Pharmaceutical University, \\ Sugitani 2630, Toyama 930-0194, Japan
}

\begin{abstract}
Neuropsychological data in humans demonstrated a pivotal role of the medial temporal lobe, including the hippocampal formation (HF) and the parahippocampal gyrus $(\mathrm{PH})$, in allocentric (environment-centered) spatial learning and memory. In the present study, the functional significance of the monkey HF and $\mathrm{PH}$ neurons in allocentric spatial processing was analyzed during performance of the spatial tasks. In the tasks, the monkey either freely moved to one of four reward areas in the experimental field by driving a cab that the monkey rode (real translocation task) or freely moved a pointer to one of four reward areas on the monitor (virtual translocation task) by manipulating a joystick. Of 389 neurons recorded from the monkey HF and $\mathrm{PH}, 166$ had place fields that displayed increased activity in a specific area in the experimental field and/or on the monitor (location-differential neurons). More HF and PH neurons re-
\end{abstract}

Recent neuropsychological data in humans have demonstrated a pivotal role of the medial temporal lobe, including the hippocampal formation (HF) and the parahippocampal gyrus (PH), in allocentric (environment-centered) spatial learning and memory. Patients with temporal lobe damages including the HF could remember neither the locations of the landmarks in space nor specific spatial relationships among the landmarks and had deficits in a radial arm maze task (Maguire et al., 1996a; Abrahams et al., 1997). Consistent with these studies, studies of normal humans with positron emission tomography (PET) and functional magnetic resonance imaging (fMRI) demonstrated that blood flow in the HF and PH increased during various types of spatial tasks using a real or realistic virtual environment (Aguirre et al., 1996; Maguire et al., 1996b; Aguirre and D’Esposito, 1997; Ghaem et al., 1997; Maguire et al., 1997).

Neurophysiological studies in rats support the human data. Activity of some HF neurons is localized to a specific location in the environment. These neurons are called "place cells" (O'Keefe and Dostrovsky, 1971; Olton et al., 1978; McNaughton et al., 1983; Eichenbaum et al., 1987; Muller and Kubie, 1987). Unitrecording studies in monkeys also reported that some primate HF neurons responded to spatial cues (Watanabe and Niki, 1985;

\footnotetext{
Received Sept. 8, 1998; revised Dec. 29, 1998; accepted Jan. 7, 1999.

This work was supported in part by the Japanese Ministry of Education, Science, and Culture Grants-in-Aid for Scientific Research (08408036, 08279105, 10680762, and 10164219) and by Funds for Comprehensive Research on Aging and Health. We thank Dr. H. Eichenbaum (Boston University, Boston, MA) for critical comments on this manuscript and Dr. P. Martin (Toyama Medical and Pharmaceutical University, Toyama, Japan) for help in preparing this manuscript.

Correspondence should be addressed to Dr. Taketoshi Ono, Department of Physiology, Faculty of Medicine, Toyama Medical and Pharmaceutical University, Sugitani 2630, Toyama 930-0194, Japan.

Copyright (C) 1999 Society for Neuroscience $\quad 0270-6474 / 99 / 192381-13 \$ 05.00 / 0$
}

sponded in the real translocation task. These neurons had low mean spontaneous firing rates (0.96 spikes/sec), similar to those of rodent HF place cells. The remaining nonresponsive neurons had significantly higher mean firing rates (8.39 spikes/ $\mathrm{sec})$, similar to interneurons or $\theta$ cells in the rodent HF. Furthermore, most location-differential neurons showed different responses in different tasks. These results suggest that the HF and $\mathrm{PH}$ are crucial in allocentric information processing and, moreover, that the HF can encode different reference frames that are context or task-dependent. This may be the neural basis of episodic memory.

Key words: hippocampal formation; parahippocampal gyrus; monkey; real translocation; virtual translocation; place cells; place fields; cognitive map; reference frame; episodic memory
Cahusac et al., 1989; Miyashita et al., 1989; Rolls et al., 1989; Feigenbaum and Rolls, 1991; Eifuku et al., 1995; Suzuki et al., 1997). Using a paradigm in which a monkey could change its location while in a motorized movable device (spatial moving task), we recently reported place correlates of the monkey HF neurons (Ono et al., 1991, 1993a,b; Nishijo et al., 1993, 1997). However, the monkeys did not freely move in our previous studies as in the studies using rodents because the external cues indicated appropriate bars to be pressed to move the cab. The HF neurons in the monkey have also been reported to respond to spatial view (Rolls and O'Mara, 1995) and whole-body motion (O'Mara et al., 1994) during the passive translocation. Although these studies indicated an importance of the HF in spatial processing, HF neurons were not tested under conditions in which the monkey could move freely. In the present study, we analyzed the activity of monkey HF neurons during performance of a task in which a monkey on the movable cab freely moved toward a destination by manipulating a joystick based on its own position as determined by the landmarks in the experimental room.

The relationship between spatial functions and episodic memory in the HF is another main issue. It has been reported that activity of HF place cells is context- or task-dependent. This suggests that the HF could encode different reference frames (or charts), which might be the neural basis of episodic memory (Nishijo et al., 1993; Kobayashi et al., 1997; Redish and Touretzky, 1997; Samsonovich and McNaughton, 1997). In the present study, to analyze task-dependent HF neuronal responses in monkeys, HF neurons were tested with the four spatial tasks (two tasks and two variants) to observe whether or not the HF neurons showed different activity in the various tasks. 
A a

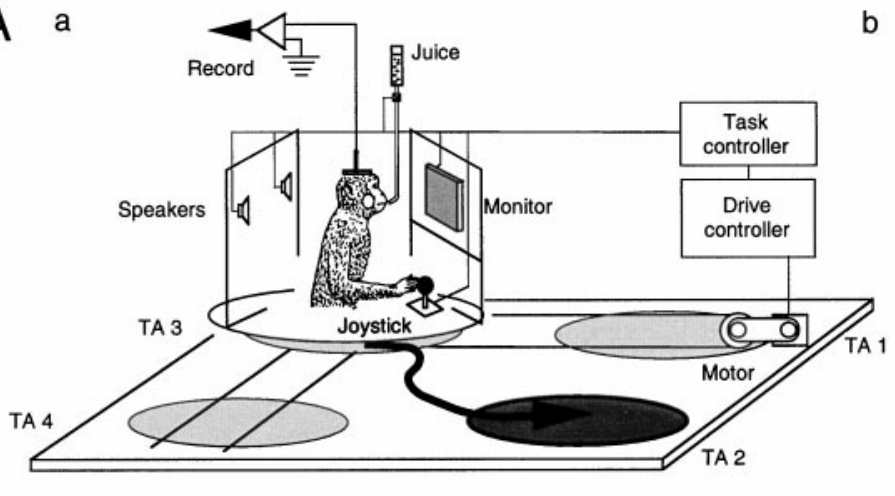

b

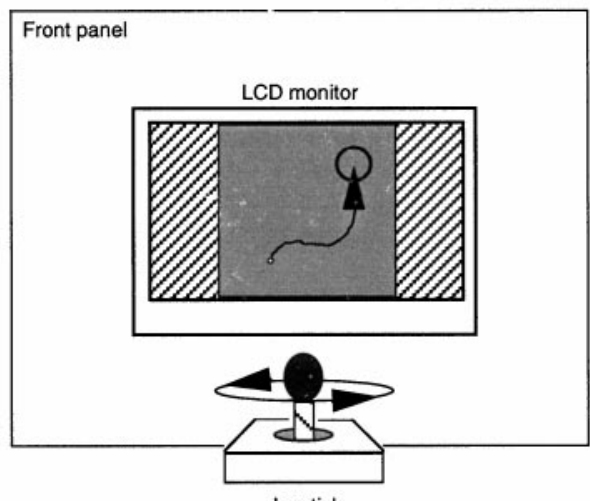

Joystick

\section{B Tone + Window frame \\ Target circle \\ Manipulating/Response
(cab and/or pointer)}

Juice

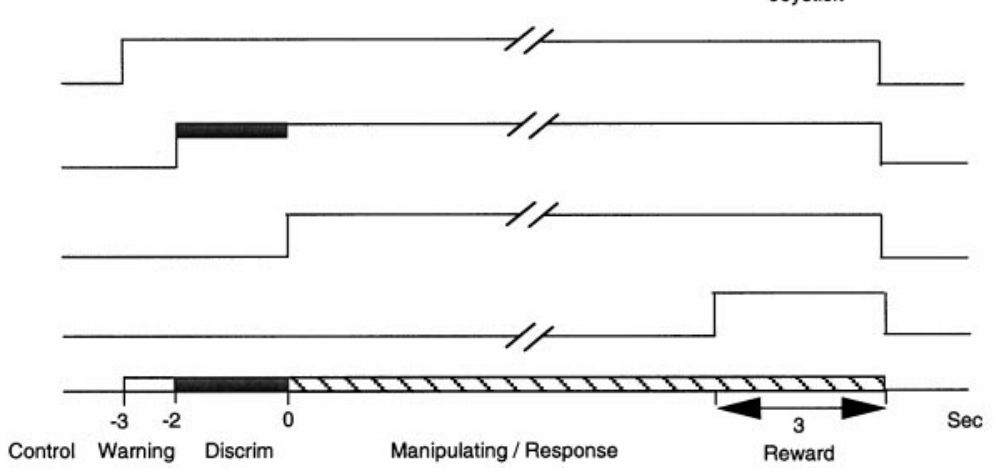

Figure 1. Schema of the experimental setup and paradigm. $A$, Freely movable monkey cab $(a)$ and front panel of the cab $(b)$. A monkey sat in a $0.7 \times$ $0.8 \times 0.85 \mathrm{~m} \mathrm{cab}$, which was freely moved in a $2.5 \times 2.5 \mathrm{~m}$ experimental field located in a $5.0 \times 6.0 \mathrm{~m}$ room. The front wall of the cab was made of transparent Plexiglass, and the rear wall was a steel plate symmetrically equipped with two speakers on the inside. On the upper part of the front wall, there was a 10.4-inch color LCD monitor with resolution of $640 \times 480$ pixels. The visual stimuli were displayed $25 \mathrm{~cm}$ from the monkey's eyes on the color LCD controlled by a microcomputer. The lower part of the front wall was equipped with a joystick to freely move a cab in the experimental field and/or a pointer (a yellow sphere with a radius of $3 \mathrm{~mm}$ ) presented on the LCD monitor. The cab and/or the pointer could be moved at constant velocity $(3 \mathrm{~cm} / \mathrm{sec}$ in real space and $2.5 \mathrm{~mm} / \mathrm{sec}$ in virtual space, respectively) in all directions during continuous manipulation of the joystick by the monkey. The movement direction of the cab and/or the pointer was linked to the direction to which the joystick was brought down by the monkey. Thick curved lines with arrows in $A a$ and $A b$ indicate examples of movements of the cab and the pointer to one of destinations indicated by thick circles [TA in $A a$ ]. Juice reward, controlled by an electromagnetic valve, was delivered from a tube that projected through the rear wall. $B$, Time sequence of the four behavioral tasks. The monkey performed the four behavioral tasks under guidance by visual stimuli on the LCD monitor and auditory stimuli from the two speakers on the back wall of the cab. The four tasks consisted of five phases: (1) pretrial control (the cab placed at a starting point); (2) warning period (a warning tone from the 2 speakers plus a window frame on the LCD monitor were presented for $1 \mathrm{sec}$ ); (3) discrimination phase (a red target circle with a radius of $1.59 \mathrm{~cm}$ appeared on the LCD monitor for $2 \mathrm{sec}$ ); (4) manipulating-response phase (the monkey manipulated the joystick); and (5) reward phase (a reward of $\sim 6 \mathrm{ml}$ of orange juice for $3 \mathrm{sec}$ was delivered).

\section{MATERIALS AND METHODS}

\section{Animals and experimental apparatus}

Two adult monkeys (Macaca fuscata), weighing 4.2 and $5.6 \mathrm{~kg}$, were used. The monkey was restrained painlessly in a stereotaxic apparatus by a surgically fixed head holder and sat in a $0.7 \times 0.8 \times 0.85 \mathrm{~m}$ high cab that could freely move in a $2.5 \times 2.5 \mathrm{~m}$ experimental field located in a $5.0 \times$ $6.0 \mathrm{~m}$ room (Fig. $1 A$ ), as modified from previous studies (Ono et al., 1991, 1993a,b; Eifuku et al., 1995; Nishijo et al., 1997). The monkey always faced toward the right of the experimental field (Fig. 1 $A a$ ). The front wall of the cab was made of transparent Plexiglas, and the rear wall was a steel plate symmetrically equipped with two speakers on the inside. In the upper part of the front wall, there was a 10.42-inch color liquid crystal display (LCD) monitor with a resolution of $640 \times 480$ pixels (LMD1040XC; Sony, Tokyo, Japan) (Fig. 1 $\mathrm{Ab}$ ). Visual stimuli were displayed $25 \mathrm{~cm}$ from the monkey on the display. The lower part of the front wall contained a joystick used to move the cab in the experimental field and/or a pointer $(\mathrm{P})$ (a yellow circle with a radius of $3 \mathrm{~mm}$ ) on the LCD monitor. The cab and/or the pointer could be moved at constant velocity (cab, $3 \mathrm{~cm} / \mathrm{sec}$ in the experimental field; pointer, $2.5 \mathrm{~mm} / \mathrm{sec}$ on the LCD monitor) in all directions during continuous manipulation of the joystick by the monkey. Acceleration of the cab was $4.5 \mathrm{~cm} / \mathrm{sec}^{2}$ to reach a constant velocity (i.e., $3.0 \mathrm{~cm} / \mathrm{sec}$ ), which was comparable to or below the vestibular threshold for humans (Young, 1984; Gianna et al., 1996). The movement direction of the cab and/or the pointer was linked to the direction to which the joystick was brought down by the monkey. Juice reward, controlled by an electromagnetic valve, was delivered from a tube that projected through the rear wall.

\section{Behavioral paradigms}

The room, illuminated at 140 lux, contained several readily identified landmarks (sink, stereomicroscope, refrigerator, table, rack, and some experimental devices) (Fig. $2 A$ ). The monkey sat in a chair within the $\mathrm{cab}$ and could see these visual landmarks in the experimental room, which were available to identify its position in the experimental field. The monkey performed four behavioral tasks under the guidance of the visual stimuli on the LCD monitor and the auditory stimuli from the two speakers on the back wall of the cab. The basic behavior required in the tasks was to either move the cab to one of four reward areas in the experimental field [target area (TA) (Figure 2A, TA1-TA4) and real translocation (RT)] or move the pointer on the LCD monitor to one of four reward areas in the four corners of the LCD monitor [target circle (TC) (Figure 2B, TC1-TC4) and virtual translocation (VT) task] by manipulating the joystick. TC1-TC4 on the LCD monitors corresponded to TA1-TA4 in the experimental field, respectively. That is, the twodimensional space on the LCD monitor was proportional to the experimental field (1:12.61). In all four tasks, the cab was initially placed at the center of one of the four target areas (starting point 1,2,3, or 4), and its position was randomly changed from trial to trial by a computer program. There were four kinds of behavioral tasks based on the combination of 
A
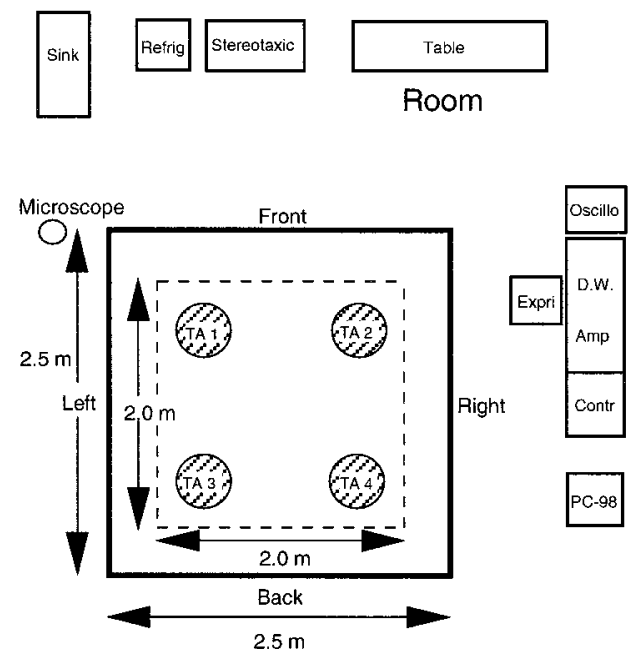

B

\section{LCD monitor}

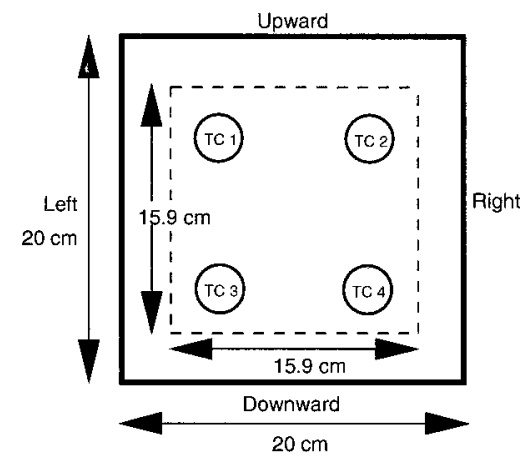

Figure 2. Spatial arrangements of room cues and target areas for the RT task $(A)$ and those of target circles on the LCD monitor for the RT and VT tasks $(B)$. $A$, The monkey sat in a chair in a cab and could see various landmarks in the experimental room, such as a stereomicroscope, a refrigerator, a table, a rack, and some experimental devices, which were available to identify its position in the experimental field. In the RT tasks, the monkey moved the cab to one of four reward areas in the four corners of the experimental field (TA1-TA4) by manipulating the joystick. Area in the thicklined box, $2.5 \times 2.5 \mathrm{~m}$ experimental field; area in the dotted-lined box, range of movement of a center of the cab where the monkey sat in a chair. Refrig, Refrigerator; Stereotaxic, stereotaxic apparatus; Oscillo, oscilloscope; Expri, experimenter; D.W., microcomputer for Datawave; Amp, main amplifier; Contr, task controller; PC-98, microcomputer for monitoring movements of the cab and joystick. $B$, A window frame indicated by a thick-lined box, which was proportional to the experimental field at the ratio of 1:12.61, appeared on the LCD monitor with a warning tone. In the VT tasks, the monkey moved a pointer on the LCD monitor to one of four reward areas in the four corners of the LCD monitor (TC1-TC4) by manipulating the joystick. In the RT tasks, one of the four target circles, each of which corresponded to each of the target areas in the experimental field, was presented on the LCD monitor to specify the destination. Area in the dotted-lined box, Range of movement of the pointer on the LCD monitor.

cab movements, indication of the pointer, and a target circle on the LCD monitor in the present study (see below).

In the real translocation task without a pointer under continuous presentation of a target circle on the LCD monitor (RT/TC), the pointer was not presented, but the target circle was continuously presented on the LCD monitor throughout the discrimination and manipulatingresponse phases. In this task, the monkey could actively move the cab toward a target area by recognizing its own location from the landmarks in the experimental room. After the cab was placed at a starting point, the task was initiated by simultaneous presentation of a warning tone $(1300 \mathrm{~Hz})$ and a $15.9 \times 15.9 \mathrm{~cm}$ blue square frame on the LCD monitor, which corresponded to the $2 \times 2 \mathrm{~m}$ experimental field for $1 \mathrm{sec}$ (warning phase) (Fig. $1 B$ ). Then, a target circle (a red circle with the radius of 1.6 $\mathrm{cm}$ ) appeared at one of the four corners of the frame on the LCD monitor. After the $2 \mathrm{sec}$ presentation of the target circle (discrimination phase), the monkey could move the cab toward the target area by manipulating the joystick (manipulating-response phase). When the monkey arrived at the target area (a circular area with the radius of 20 $\mathrm{cm}$ ) indicated by the target circle on the LCD monitor, a reward of $\sim 6 \mathrm{ml}$ of orange juice was presented for $3 \mathrm{sec}$ (reward phase). After delivery of juice, the warning tone stopped, and the blue square frame and the target circle disappeared. If the monkey failed to move to the target area within $120 \mathrm{sec}$, reward was withheld and the trial was terminated. After the end of each trial, the cab was moved to the next starting point under control of the computer. The time interval between trials was 30-60 sec. Thus, the RT/TC task consisted of 5 phases: (1) pretrial control phase (the cab placed at a starting point); (2) warning phase (1 sec); (3) discrimination phase (2 sec); (4) manipulating-response phase; and (5) reward phase (3 sec).

In the real translocation task with the pointer under continuous presentation of a target circle on the LCD monitor (RT/P-TC), the task sequence and behavioral requirements were similar to those in the $\mathrm{RT} / \mathrm{TC}$ task, except that the pointer, indicating the location of the cab, was also shown on the LCD monitor. That is, the monkey had a map on a scale ratio of 1:12.61 and a car navigator in the RT/P-TC task. The task phases were similar to those of the RT/TC task.

In the virtual translocation task with the pointer (VT/P), the cab was located stationarily at a starting point throughout the trial. In this task, a target circle was transiently presented on the LCD monitor only during the discrimination phase. Therefore, the monkey was required to memorize the location of the target circle during the discrimination phase and to move the pointer to the location based on memory by manipulating the joystick during the manipulating-response phase. The task phases were similar to those in the RT/TC task.

In the virtual translocation task with a pointer under continuous presentation of a target circle on the LCD monitor (VT/P-TC), the task sequence and behavioral requirements were similar to those in the VT/P task, except that a target circle was presented not only during the discrimination phase for $2 \mathrm{sec}$ but also during the manipulating-response phase. The task phases were similar to those in the RT/TC task.

\section{Training and surgery}

The monkey was initially trained to learn the VT/P-TC task. However, the monkey was required to move the pointer on the LCD monitor in fixed directions (i.e., forward-backward, leftward-rightward, or diagonally) by manipulating a joystick that had physical limitations of movements. It took $\sim 2-3$ months for the monkey to learn moving the pointer freely in all directions using a joystick without physical limitations. When the monkey learned to perform the VT/P-TC task with a criterion of $95 \%$ correct responses, it was then trained on the $\mathrm{VT} / \mathrm{P}$ task. The monkey required $\sim 3$ months of training to reach $95 \%$ performance in the $\mathrm{VT} / \mathrm{P}$ task. In the next stage, the monkey was trained to learn the $\mathrm{RT} / \mathrm{P}-\mathrm{TC}$ task. It learned the task very easily. After learning these three tasks with $95 \%$ performance, the monkey was trained in the RT/TC task. It took $\sim 5$ months of training for it to reach $95 \%$ performance. In the final stage, the monkey was well trained and performed all tasks for 3 weeks. The monkey was trained for $3 \mathrm{hr} / \mathrm{d}$ and $5 \mathrm{~d} /$ week.

After completion of this training period, a head-restraining device (a U-shaped aluminum plate) was attached to the skull under aseptic condition and sodium pentobarbital anesthesia $(35 \mathrm{mg} / \mathrm{kg}$, i.m.). The plate was anchored with dental acrylic to stainless steel bolts inserted in keyhole slots in the skull. During the surgery, heart and respiratory functions and rectal temperature were monitored on a polygraph system (Nihon Kohden, Tokyo, Japan). The rectal temperature was controlled at $37 \pm 0.5 \mathrm{C}^{\circ}$ by a blanket heater. Antibiotics were administrated topically and systemically for 1 week to protect against infection. Two weeks after surgery, the monkey was retrained. Performance criterion was again attained in $\sim 10 \mathrm{~d}$. All monkeys were treated in strict compliance with the policy of the NIH Standards for Treatment of Laboratory Animals.

\section{Recording procedures and data acquisition}

A glass-insulated tungsten microelectrode $(1-2 \mathrm{M} \Omega$ at $1000 \mathrm{~Hz}$ ) was stereotaxically inserted vertically into the $\mathrm{HF}$ and $\mathrm{PH}$ stepwise by a pulse motor-driven manipulator (SM-21; Narishige, Tokyo, Japan). The location of the HF and $\mathrm{PH}$ was determined based on the stereotaxic coordinates of an atlas of M. fuscata (Kusama and Mabuchi, 1970) and x-ray photography. Extracellular activity was passed through a high-input impedance preamplifier (PHS-16; Nihon Kohden), amplified by a main amplifier (DPA-2016; Dia Medical System Co.), monitored on an oscilloscope, and recorded on a video tape by a data recorder (RX-8000; TEAC, Tokyo, Japan). The outputs from the amplifier were digitized and 
sent to an IBM-compatible 486-based microcomputer. The software (Enhanced Discovery and Autocut; Datawave Corporation) collected an epoch of the digitized analog signal for every event that exceeded a user-set threshold. Usually one to three single units were isolated by means of off-line cluster analysis (Autocut) from these data. The digital outputs of $x$ and $y$ coordinates of the cab and/or pointer were simultaneously displayed on-line on another microcomputer (PC-9821; NEC, Tokyo, Japan). In addition, autocorrelograms were made for each neuron to check for a refractory period, which must be $\geq 1-2 \mathrm{sec}$.

In each task, there were 12 different combinations of starting points and target areas (i.e., four different starting points $\times$ three different target areas), and at least these 12 kinds of trials (one session) were run for each HF and PH neuron isolated in each task. During recording, eye movements were also monitored by an eye monitor system using an infrared CCD camera (EM100; Toyo Sangyo Co., Ltd.).

\section{Data analysis}

Firing rate maps. In the studies of place cells of freely moving rats (Muller and Kubie, 1987; Breese et al., 1989), the time of occurrence for the spikes of a given HF or PH neuron, along with the location data, has been used to construct a firing rate map for each neuron. In the present study, we made use of this method to visualize firing patterns with respect to location of the monkey in the experimental field in the RT/TC and $\mathrm{RT} / \mathrm{P}-\mathrm{TC}$ tasks. Because the center of the cab where the monkey sat in a chair could be translocated within a range of a $2.0 \times 2.0 \mathrm{~m}$ square area in the experimental field (Fig. $2 A$, dotted-lined square), this $2.0 \times 2.0$ square movable area was divided into $25 \times 25 \mathrm{~cm}$ pixels by an $8 \times 8$ array. The mean firing rate for each pixel was obtained by dividing the total number of spikes that occurred when the monkey was in that location by the total time spent in that location. That is, the mean firing rate for each pixel was calculated as the average spikes per second for all visits to that pixel during translocation (i.e., manipulating-response and reward phases). Then, a grand mean firing rate (M) was calculated by averaging the mean firing rate in each pixel. Neuronal activity in each pixel was expressed as a relative firing rate $(R)$ in which the mean firing rate in each pixel was divided by the grand mean in each task and is shown in five steps $(\mathrm{R} \geq 2.0 \mathrm{M} ; 2.0 \mathrm{M}>\mathrm{R} \geq 1.5 \mathrm{M} ; 1.5 \mathrm{M}>\mathrm{R} \geq 1.0 \mathrm{M}$; $1.0 \mathrm{M}>\mathrm{R} \geq 0.5 \mathrm{M} ; \mathrm{R}<0.5 \mathrm{M})$.

In the $\mathrm{VT} / \mathrm{P}$ and $\mathrm{VT} / \mathrm{P}-\mathrm{TC}$ tasks, the pointer could be translocated in the $15.9 \times 15.9 \mathrm{~cm}$ movable area on the LCD monitor (Fig. $2 B$, dottedlined square), which corresponded to the $2.0 \times 2.0 \mathrm{~m}$ square movable area in the experimental field. This movable area on the LCD monitor was also divided into $1.98 \times 1.98 \mathrm{~cm}$ pixels by an $8 \times 8$ array. A firing rate map for each $\mathrm{HF}$ and $\mathrm{PH}$ neuron with respect to location of the pointer on the LCD monitor was similarly obtained as in the RT tasks.

Place field. In previous studies, place fields have been quantified based on the reliability of increased firing during repeated visits to a given location (Muller and Kubie, 1987; O'Keefe and Speakman, 1987;Breese et al., 1989; Wilson and McNaughton, 1993; Kobayashi et al., 1997). Because movement speed of the cab was very slow (i.e., $3 \mathrm{~cm} / \mathrm{sec}$ ) in the present study, the total amount of time taken to visit each pixel was relatively long (usually $>8.3 \mathrm{sec} / \mathrm{pixel}$ ). To determine the boundary of the place field of the HF and PH neurons in the RT/TC and RT/P-TC tasks, we compared the mean firing rate of each pixel with a grand mean. An increase in mean firing rates in each pixel was defined as that greater than 2.0 times the grand mean firing rate for a given neuron. This criterion was similar to those in the previous studies (Muller and Kubie, 1987; Kobayashi et al., 1997). Clusters of $25 \times 25 \mathrm{~cm}$ pixels in the experimental field with mean firing rates exceeding both 1.5 and 2.0 times the grand mean firing rate were identified. All pixels that did not satisfy this criterion were eliminated. Only place fields that had at least one pixel with a mean firing rate exceeding 2.0 times the grand mean and one adjacent pixel with a mean firing rate exceeding 1.5 times the grand mean were analyzed. Place fields could be expanded through any edge shared by two pixels meeting the criterion (greater than 1.5 times the grand mean). If one or more neighboring pixels satisfied the criterion, the field was expanded to include the pixel(s). Each added pixel was then tested for the presence of a neighboring pixel that met the criterion. When no neighboring pixel satisfied the criterion, the limit of the field was identified. Boundaries of a place field were established by constructing a rectangle that had one diagonal connecting the minimum $x$ and $y$ coordinates with the maximum $x$ and $y$ coordinates. The size of the firing field for a given neuron was expressed as a percentage of the total area it occupied in the square: number of pixels in the place field divided by the total number of pixels visited by the monkey. In the VT/P and
VT/P-TC tasks, clusters of $1.98 \times 1.98 \mathrm{~cm}$ pixels on the LCD monitor with mean firing rates exceeding both 1.5 and 2.0 times of the grand mean firing rate were identified. The place fields on the LCD monitor in the $\mathrm{VT} / \mathrm{P}$ and VT/P-TC tasks were similarly obtained as in the RT/TC and RT/P-TC tasks. The HF and PH neurons that had place fields at least in one task were defined as location-differential neurons. These neurons were comparable to rodent place cells (pyramidal neurons) (for details, see Results, Spontaneous firing rates of the HF neurons).

Overlap of place fields across the tasks. Spatial locations of the place fields in the four tasks could be compared because each pixel on the LCD monitor corresponded to that in the experimental field. Place fields were judged to overlap if they shared at least one same corresponding pixel in different tasks.

\section{Histology}

After the last recording session, several small marking lesions were made in the $\mathrm{HF}$ and the $\mathrm{PH}$ by passing $20-30 \mu \mathrm{A}$ of anodal current for $30 \mathrm{sec}$ through an electrode placed stereotaxically and was monitored by $\mathrm{x}$ ray. Subsequently, the monkey was deeply anesthetized with an overdose of sodium pentobarbital $(50 \mathrm{mg} / \mathrm{kg}$, i.m.) and perfused transcardially with $0.9 \%$ saline, followed by $10 \%$ buffered formalin. The brains were removed from the skulls and cut into $50 \mu \mathrm{m}$ sections through the HF. Sections were stained with cresyl violet, and sites of electrical lesions were determined microscopically. The location of each recording site was then calculated by comparing the stereotaxic coordinates of recording sites with those of lesions. The positions of the HF and PH and of the recording electrodes were checked by x-ray photography during the experiments, and these photographs were compared with those of the marking electrodes to verify the calculated recording sites.

\section{RESULTS}

The activity of 389 neurons was recorded from the monkey HF and $\mathrm{PH}$. Of these neurons, $166(42.7 \%)$ had place fields in the

\section{Table 1. Summary of types and numbers of the monkey hippocampal} neurons

\begin{tabular}{lcr} 
Neuronal type & $\mathrm{N}(\mathrm{C} / \mathrm{P})^{*}$ & $(\%)$ \\
\hline Location-differential responses & 166 & 42.7 \\
RT/TC-responsive & & \\
RT/TC only & 41 & 10.5 \\
RT/TC + RT/P-TC & $9(2 / 0)$ & 2.3 \\
RT/TC + RT/P-TC + VT/P & $9(0 / 2)$ & 2.3 \\
RT/TC + RT/P-TC + VT/P + VT/P-TC & $11(0 / 1)$ & 2.8 \\
RT/TC + RT/P-TC + VT/P-TC & $13(0 / 2)$ & 3.4 \\
RT/TC + VT/P & $11(0 / 0)$ & 2.8 \\
RT/TC + VT/P + VT/P-TC & $19(2 / 4)$ & 4.9 \\
RT/TC + VT/P-TC & $6(1 / 0)$ & 1.6 \\
Total & 119 & 30.6 \\
RT/P-TC-responsive without responses to & & \\
RT/TC & & \\
RT/P-TC only & 16 & 4.2 \\
RT/P-TC + VT/P & $7(0 / 0)$ & 1.8 \\
RT/P-TC + VT/P + VT/P-TC & $3(0 / 0)$ & 0.9 \\
RT/P-TC + VT/P-TC & $5(0 / 0)$ & 1.3 \\
Total & 31 & 8.0 \\
Non-responsive to RT & & \\
VT/P only & 7 & 1.8 \\
VT/P + VT/P-TC & $5(3 / 0)$ & 1.3 \\
VT/P-TC only & 4 & 0.9 \\
Total & 16 & 4.1 \\
No response & 223 & 57.3 \\
Total & 389 & 100.0 \\
& & \\
& &
\end{tabular}

*Indicates numbers of neurons that had overlapped place fields across all the tasks in which given neurons had place fields (complete overlap, C) and those neurons that had overlapped place fields in some but not all of the tasks (partial overlap, P), respectively. 


\section{$A$ a. Real translocation without a pointer}
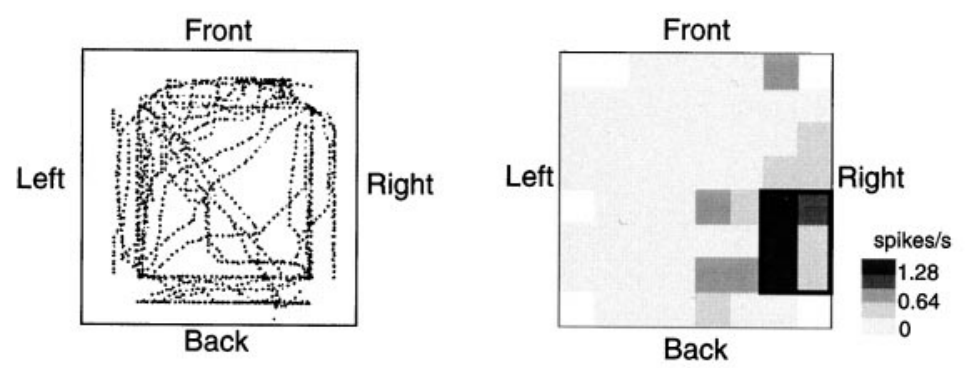

b

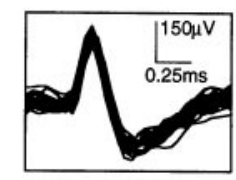

C

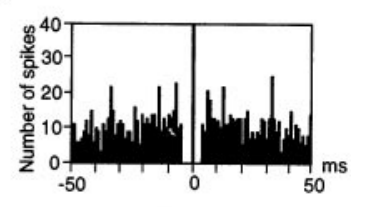

\section{B a. Real translocation without a pointer}

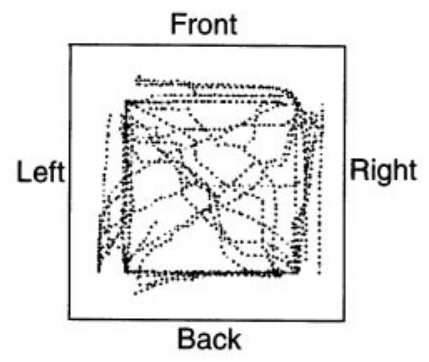

Trail map

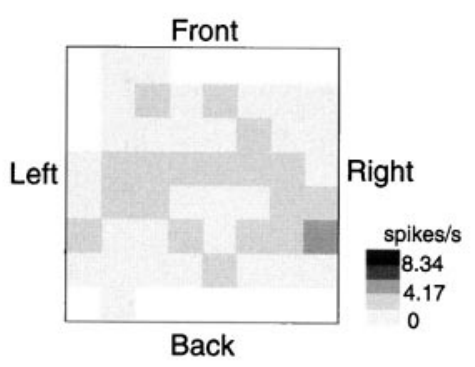

Firing rate map b

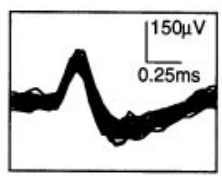

C

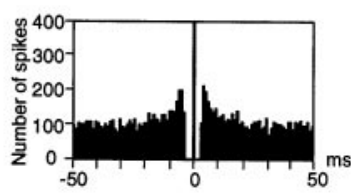

Figure 3. Two typical examples of the HF neurons. $A$, An example of an HF neuron with location-differential responses. Aa, The trail of the cab (left panel) and the corresponding location-differential responses (right panel) in the RT/TC task. A place field is surrounded by thick lines. Calibration is shown at the right; a mean firing rate for each pixel was expressed as a relative firing rate in which the mean firing rate in each pixel was divided by the grand mean firing rate in each task and was shown in five steps $(\mathrm{R} \geq 2 \mathrm{M} ; 2.0 \mathrm{M}>\mathrm{R} \geq 1.5 \mathrm{M} ; 1.5 \mathrm{M}>\mathrm{R} \geq 1.0 \mathrm{M} ; 1.0 \mathrm{M}>\mathrm{R} \geq 0.5 \mathrm{M} ; \mathrm{R}<0.5 \mathrm{M})$. Three values in the calibration indicate those of $2 \mathrm{M}, \mathrm{M}$, and 0 , respectively. Regions not visited by the monkey during the session(s) are shown by blank pixels. Note that the activity increased in the right back corner of the experimental field, although the monkey moved and visited various sites of the experimental field and received juice reward at the four corners of the experimental field. $A b$, Superimposed spike waves of the HF neuron shown in Aa. Ac, Autocorrelogram of the HF neuron shown in Aa. Ordinate, Number of spikes; abscissa, time in msec; bin size, 1 msec. Note that a refractory period of the neuron was $2-3 \mathrm{msec}$, which indicated that these spikes were recorded from a single neuron. $B$, An example of an HF neuron without location-differential responses. Note that no place fields were observed. Other descriptions as in $A$.

experimental field and/or on the LCD monitor. Of these 166, 119 $(30.6 \%)$ had place fields during performance of the RT/TC task (RT/TC-responsive), $31(8.0 \%)$ during the RT/P-TC task but not during the RT/TC task (RT/P-TC-responsive without responses to RT/TC), and 16 (4.1\%) only during the VT tasks (nonresponsive to RT/TC and RT/P-TC tasks). These HF and PH neurons were further subcategorized into several groups based on the responsiveness in the four tasks. Table 1 summarizes the numbers of different subcategories of $\mathrm{HF}$ and $\mathrm{PH}$ neurons recorded in the present study.

\section{Location-differential responses}

Figure 3 shows two examples of HF neurons with and without location-differential responses. The trail of the cab and the corresponding location-differential responses in the RT/TC task are illustrated in Figure $3 A$. The trail of the cab was shown as dotted lines in which each dot corresponded to a position of a center of the cab at each moment (Fig. 3A, left panel). Although the monkey moved and visited various sites of the experimental field and received juice rewards in the four corners of the experimental field, the activity increased in the right back corner of the experimental field (Fig. $3 A$, right panel). Superimposed spike waves of the HF neuron and the autocorrelogram of the neuronal spikes are shown in Figure 3, $A b$ and $A c$, respectively. The autocorrelogram indicated that a refractory period of the neuron was $2-3$ msec, which indicated that these spikes were recorded from a single neuron. On the other hand, the neuron shown in Figure $3 B$ exhibited no location-differential responses $(a)$, although the waveform and autocorrelogram indicated that the neuronal spikes were recorded from a single neuron $(b, c)$. Based on its relatively high mean firing rate (4.17 spikes/sec) and lack of spatial specificity, it is most probable that this neuron was an interneuron rather than a pyramidal neuron (for details, see Results, Spontaneous firing rates of the HF neurons).

Figure 4 shows an example of an HF neuron that was tested with the same task in several sessions (the same neuron shown in Fig. 3A). The neuron was tested in three successive sessions (36 trials) in the RT/TC task. In each session, a place field was observed in the right back corner of the experimental field. The place fields in these three sessions overlapped and were highly consistent. Repeated testing of the 24 neurons (locationdifferential, 8; nonresponsive, 16) indicated that activity of all the neurons was highly consistent across the sessions; place fields of the location-differential neurons overlapped across the sessions, and nonresponsive neurons remained nonresponsive across ses- 
A

a

RT/TC 1st

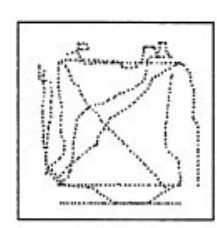

B

RT/TC 2nd

a

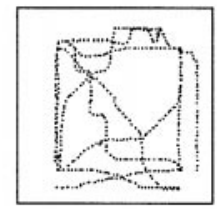

C

$\mathrm{RT} / \mathrm{TC} 3 \mathrm{rd}$

a

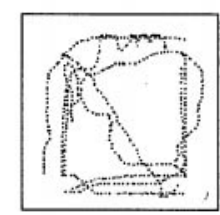

D

Average

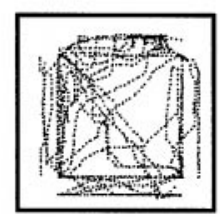

Trail map b

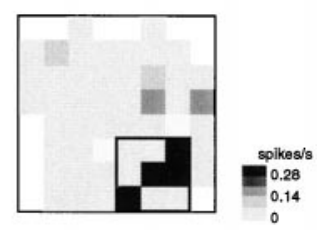

b

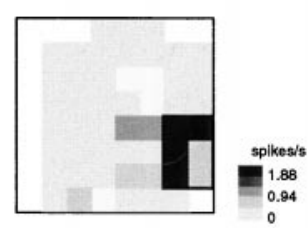

b

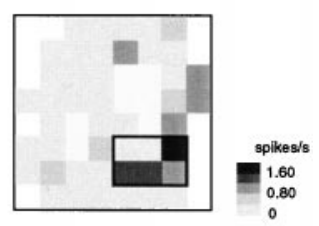

b

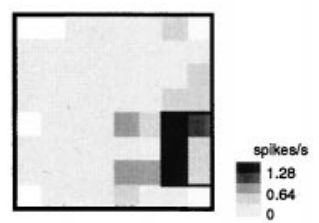

Firing rate map

Figure 4. Trails of a cab and firing rate maps of the HF locationdifferential neuron shown in Figure $3 A$ during the successive three sessions in the RT/TC task. $A-C$, Individual trail and firing rate maps during the three sequential sessions in the RT/TC task. $D$, Average trail and firing rate maps during the three sequential sessions in the RT/TC task. Note that the place fields in these three sessions overlapped and were highly consistent. Other descriptions as in Figure 3.

sions. This stability of the HF neuronal responses were consistent with the results of previous studies in rat HF place cells when rats were run in fixed conditions (Muller and Kubie, 1987; Thompson and Best, 1990; Kobayashi et al., 1997; Barnes et al., 1997).

Figure 5 shows the relationship between eye positions and neuronal activity of the same neuron shown in Figures $3 A$ and 4 during the RT/TC task. Figure $5, A-C$, represented neuronal activity when the monkey drove the cab outside the place field $(A)$, moved to the place field $(B)$, and moved away from the place field ( $C$ ), respectively. The trails of the cab in $A-C$ are shown in Figure $5 D$. No neuronal activity was observed in $A$ when the monkey moved outside the place field. In $B$ and $C$, neuronal activity was observed only when the monkey moved within or near the place field. It should be noted that active eye movements were observed in these three trials (Fig. $5 A-C$, Eye trace), regardless of the neuronal activity. This indicated no correlation between eye movements and neuronal activity. No neurons recorded in the present study showed correlation to eye movements, as shown in Figure 5.

\section{Responsiveness of the HF and PH neurons across the tasks}

There were differences in ratios of responsive neurons among the tasks (Table 1). Of the 166 location-differential $\mathrm{HF}$ and $\mathrm{PH}$ neurons, $150(90.4 \%)$ had place fields in the RT tasks (RT/TC and RT/P-TC), whereas $100(60.2 \%)$ had place fields in the VT tasks (VT/P and VT/P-TC). The difference in ratios was statistically significant (Fisher's exact probability test; $p<0.01$ ). Furthermore, when responsiveness of the $\mathrm{HF}$ and $\mathrm{PH}$ neurons to two RT tasks was compared, the ratio of the $\mathrm{HF}$ and $\mathrm{PH}$ neurons that had place fields in the RT/TC task (71.7\%, 119 of 166) was significantly larger than that of $\mathrm{HF}$ and $\mathrm{PH}$ neurons that had place fields in the RT/P-TC task (44.0\%, 73 of 166) (Fisher's exact probability test; $p<0.01)$.

Figure 6 illustrates an example of an RT/TC-responsive $\mathrm{HF}$ neuron that had place field(s) only in the RT/TC task (Table 1, $\mathrm{RT} / \mathrm{TC}$ only). The neuron had two place fields in the left front corner of the experimental field (Fig. 6A). Although the monkey moved in the same experimental field, no place fields were observed in the RT/P-TC task (Fig. $6 B$ ). In the other two VT tasks, no place fields were observed (Fig. $6 C, D$ ). Figures 7 and 8 show two examples of RT/TC-responsive HF and PH neurons that had place fields not only in the RT/TC task but also in other tasks. The HF neuron shown in Figure 7 had place fields in the RT/TC, $\mathrm{RT} / \mathrm{P}-\mathrm{TC}$, and VT/P tasks (Table 1, RT/TC + RT/P-TC + $\mathrm{VT} / \mathrm{P}$ ), whereas the HF neuron shown in Figure 8 had place fields in the RT/TC, VT/P, and VT/P-TC tasks (Table 1, RT/TC + $\mathrm{VT} / \mathrm{P}+\mathrm{VT} / \mathrm{P}-\mathrm{TC})$.

An example of the HF neuron that had place fields in the $\mathrm{RT} / \mathrm{P}-\mathrm{TC}$ but not the RT/TC tasks (Table 1, RT/P-TC-responsive without responses to RT/TC) is shown in Figure 9. The HF neuron had place fields in both the RT/P-TC and VT/P-TC tasks. Figure 10 illustrates an example of the $\mathrm{HF}$ and $\mathrm{PH}$ neurons that had place fields only in the VT tasks. The neuron had place fields in both the VT/P and VT/P-TC tasks (Table 1, VT/P + VT/P-TC).

\section{Correlation of the place fields across the tasks}

Of the 166 location-differential neurons, 68 had place field(s) only in one task (Table 1). Of the remaining 98 neurons that had place fields in more than two tasks, only $17(10.2 \%, 17$ of 166$)$ neurons had overlapped place fields across the tasks. An example of the $\mathrm{HF}$ and $\mathrm{PH}$ neurons that had nonoverlapped place fields is shown in Figure 11. The HF neuron had two place fields in the right forward corner of the experimental field in the RT/TC task $(A)$, whereas the neuron had one place field in the left lower corner of the LCD monitor in the VT/P-TC task $(D)$.

On the other hand, of the 17 neurons that had overlapped place fields, nine had overlapped place fields only in some but not all the tasks in which given neurons had place fields (Table 1, partial overlap). Figures 7 and 8 show two examples of the HF neurons that had partially overlapped place fields. The place fields of the HF neuron shown in Figure 7 in the RT/TC and RT/P-TC tasks were overlapped $(A, B)$ but not with the place field in the VT/P task $(C)$. The place fields of the HF neuron shown in Figure 8 in the $\mathrm{RT} / \mathrm{TC}$ and VT/P tasks were overlapped $(A, C)$ but not with the place field in the VT/P-TC task $(D)$. Figures 9 and 10 show two examples of the HF and PH neurons that had completely overlapped place fields. The place fields of the HF neuron shown in Figure 9 in the RT/P-TC and VT/P-TC tasks were overlapped $(B, D)$, whereas the place fields of the HF neuron shown in Figure 10 in the $\mathrm{VT} / \mathrm{P}$ and $\mathrm{VT} / \mathrm{P}$-TC tasks were overlapped $(C, D)$. 
A

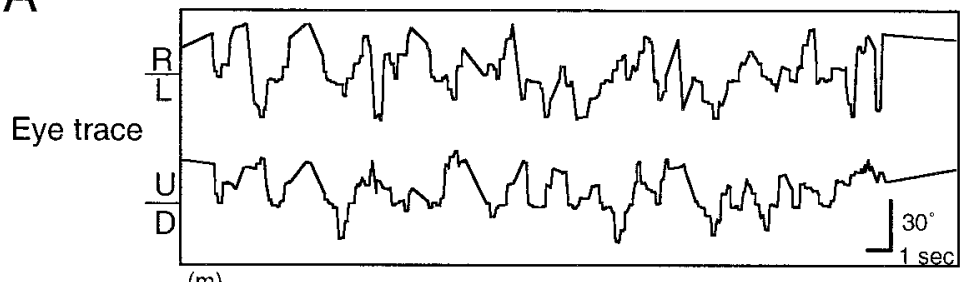

Cab

location ${ }_{0}^{2(m)}$
D

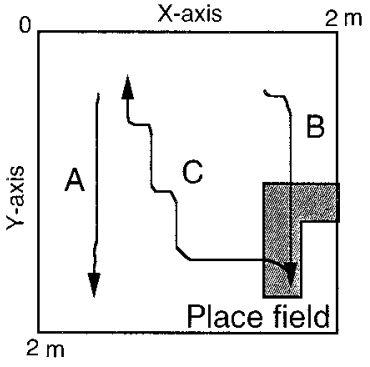

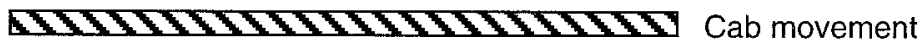

Raster

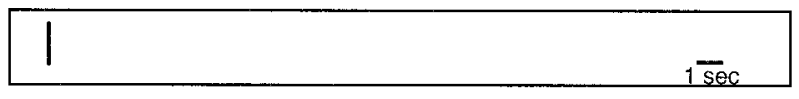

B

Eye trace

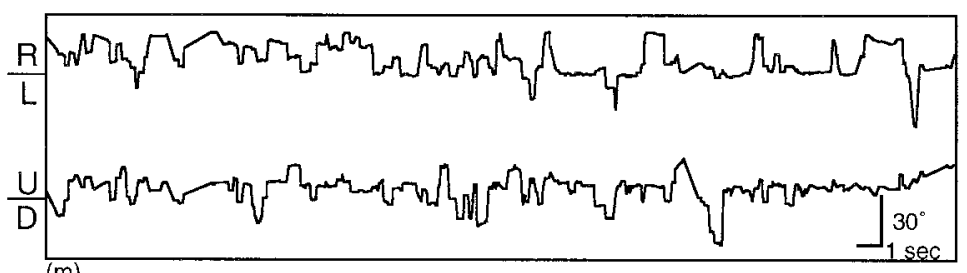

Cab

location

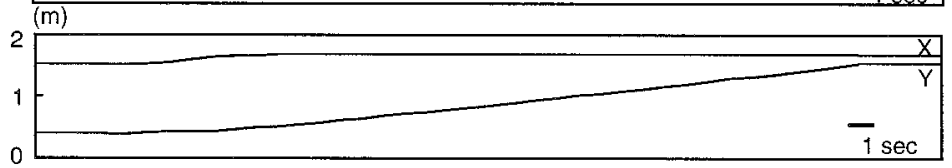

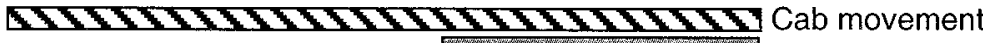

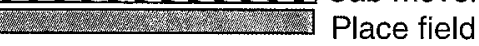

Raster

C

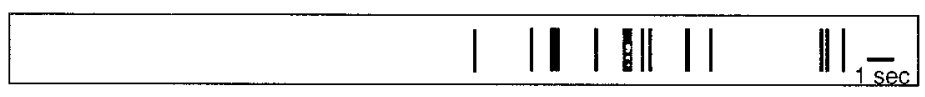

Eye trace

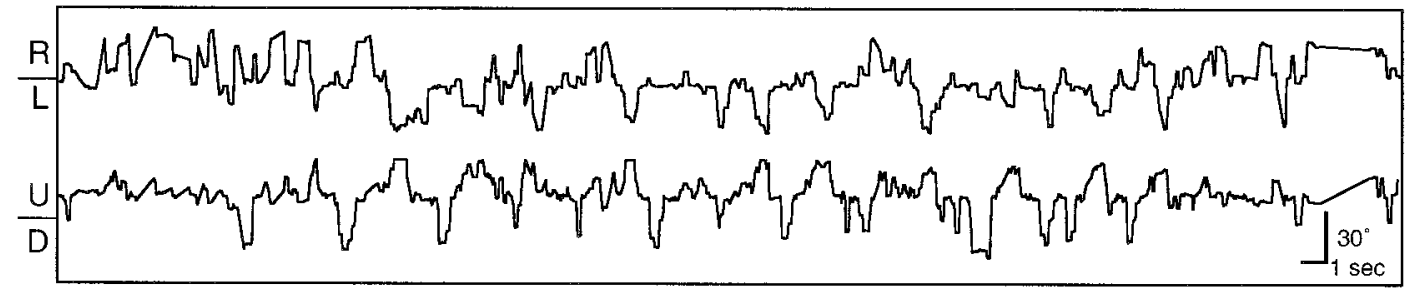

Cab location

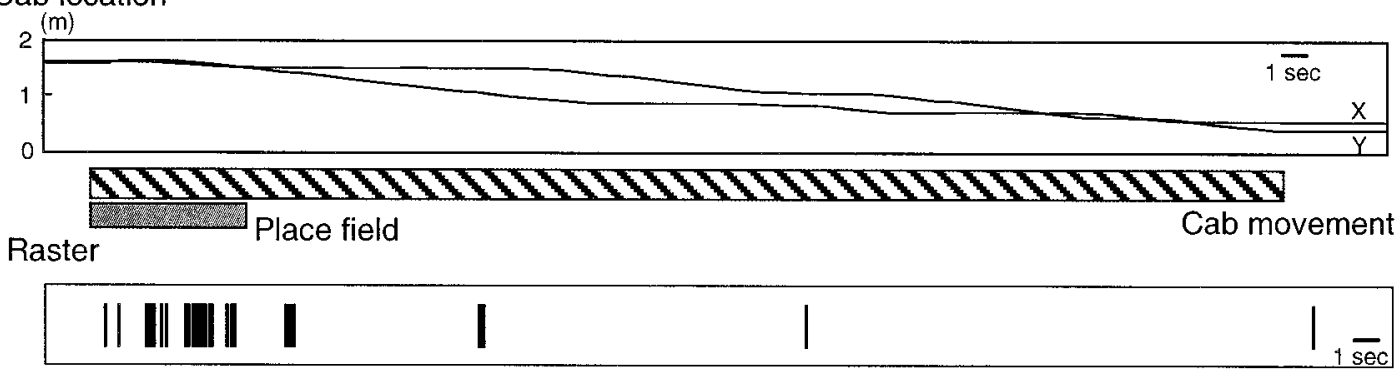

Figure 5. Relationship between eye movements and activity of the neuron shown in Figures 3 and 4 during the RT/TC task. $A-C$, Independent activity of the neurons, regardless of eye movements. Eye trace, Left eye positions; Cab location, location indicated by coordinates in $x$ - and $y$-axes; $X$, coordinates in $x$-axis; $Y$, coordinates in $y$-axis; Raster, raster display of neuronal activity. $R$, Right; $L$, left; $U$, up; $D$, down. Hatched bars, Duration of cab movements; light stippled areas, duration during which a cab was located within a place field of the neuron. $D$, Trials of a cab during the RT/TC task. Trails indicated by labels $A, B$, and $C$ in $D$ correspond to cab movements in panels $A-C$. Place fields of the neurons are shown by a light stippled area. Arrows, Directions of cab movements. 
A

a

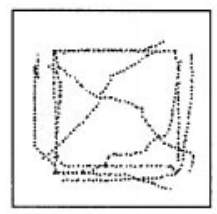

B

RT/P-TC

a

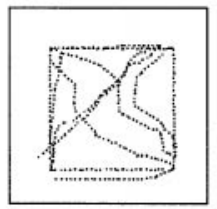

C

VT/P

a

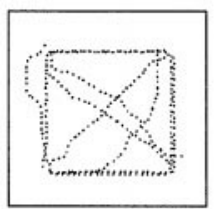

D

VT/P-TC b

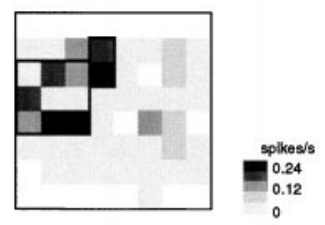

b

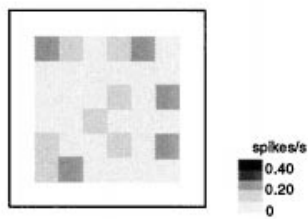

b

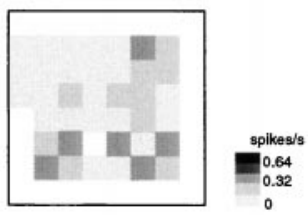

b

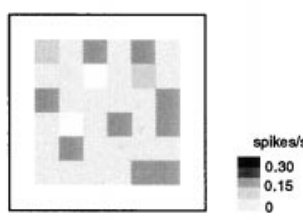

Firing rate map
A

$\mathrm{RT} / \mathrm{TC}$

B

RT/P-TC

C

VT/P
Trail map

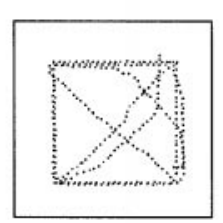

Figure 6. An example of trail and firing rate maps of the RT/TCresponsive HF neurons that had place fields only in the RT/TC tasks (Table 1, RT/TC only). Note that the neuron had two place fields at the left front corner of the experimental field in the RT/TC tasks $(A)$. Other descriptions as in Figure 3.

Thus, although some HF neurons had overlapped place fields across the tasks, there was no pattern in the combination of tasks in which the place fields overlapped.

\section{Sizes of the place fields}

Figure $12 A$ represents actual sizes of individual place fields for 166 location-differential $\mathrm{HF}$ and $\mathrm{PH}$ neurons in the four different tasks. The 119, 73, 72, and $66 \mathrm{HF}$ and $\mathrm{PH}$ neurons had place fields in the RT/TC $(A a), \mathrm{RT} / \mathrm{P}-\mathrm{TC}(A b), \mathrm{VT} / \mathrm{P}(A c)$, and VT/P-TC $(A d)$ tasks, respectively. The place fields were randomly distributed and covered most areas of the experimental field and the LCD monitor. The relative sizes of the place fields are shown in Figure $12 \mathrm{~B}$. The relative size of a place field for a given neuron was defined as a percentage of the number of pixels in the place field of the given neuron divided by the total number of pixels visited by the monkey. The relative sizes of the place fields in the four tasks ranged from 3.6 to $33.3 \%(10.5 \pm 0.3 \%$; mean $\pm \mathrm{SE}$; $n=330)$. There were significant differences in the relative sizes of the place fields among the four different tasks (one-way ANOVA; $\left.F_{(3,326)}=5.654 ; p<0.01\right)$. The post hoc test indicated that the mean relative size of the place fields in the VT/P-TC was significantly larger than those in the RT/TC, RT/P-TC, and VT/P tasks (Newman-Keuls test; $p<0.05$ ).
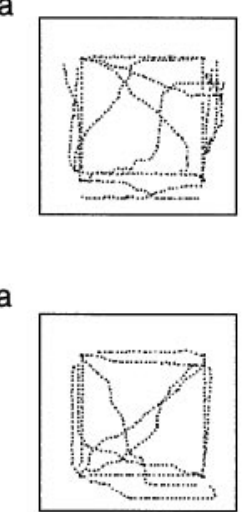

b

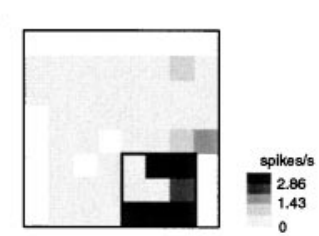

b

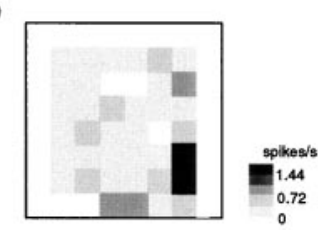

a

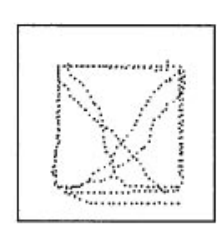

b

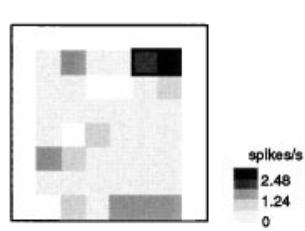

a

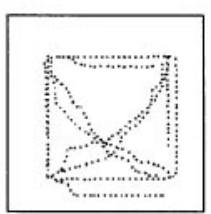

Trail map b

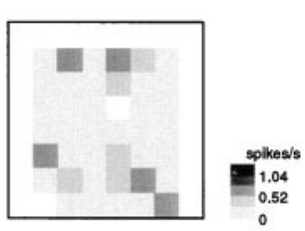

Firing rate map

Figure 7. An example of trail and firing rate maps of the RT/TCresponsive HF neurons that had place fields in the RT/TC, RT/P-TC, and $\mathrm{VT} / \mathrm{P}$ tasks (Table $1, \mathrm{RT} / \mathrm{TC}+\mathrm{RT} / \mathrm{P}-\mathrm{TC}+\mathrm{VT} / \mathrm{P})$. Note that the HF neurons had partially overlapped place fields. In the RT/TC $(A b)$ and $\mathrm{RT} / \mathrm{P}-\mathrm{TC}(B b)$ tasks, the place fields in the right back area of the experimental field overlapped, but place field was located around the right forward area on the window frame of the LCD monitor in the VT/P task $(\mathrm{Cb})$. Other descriptions as in Figure 3.

\section{Spontaneous firing rates of the HF neurons}

There were significant differences in mean firing rates between location-differential and nonresponsive HF and PH neurons. The mean firing rates of the 166 location-differential $\mathrm{HF}$ and $\mathrm{PH}$ neurons ranged from 0.01 to 13.22 spikes/sec $(0.96 \pm 0.14 ; n=$ 166), whereas those of nonresponsive $\mathrm{HF}$ and $\mathrm{PH}$ neurons ranged from 0.01 to 50.3 spikes/sec $(8.39 \pm 0.87 ; n=223)$. The grand mean firing rate of the all nonresponsive $\mathrm{HF}$ and $\mathrm{PH}$ neurons was significantly larger than that of the location-differential HF and PH neurons (Student's two-tailed $t$ test; $p<0.01$ ). There were also significant differences in the mean firing rates among the four types of the HF and PH neurons. The frequency histogram of the mean firing rates of the four types of $\mathrm{HF}$ and $\mathrm{PH}$ neurons is shown in Figure $13 A$. Most of the location-differential $\mathrm{HF}$ and $\mathrm{PH}$ neurons had low mean firing rates $(<5$ spike/sec), whereas mean firing rates of the nonresponsive $\mathrm{HF}$ and $\mathrm{PH}$ neurons distributed very widely from low to high mean firing rates. Grand mean firing rate of each type of the $\mathrm{HF}$ and $\mathrm{PH}$ neurons is indicated in Figure $13 B$. There were significant differences in the grand mean firing rates among the four types of the $\mathrm{HF}$ and $\mathrm{PH}$ neurons (one-way 
A
RT/TC

a

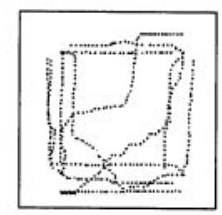

B

RT/P-TC

a

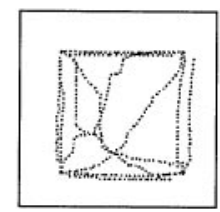

C

VT/P

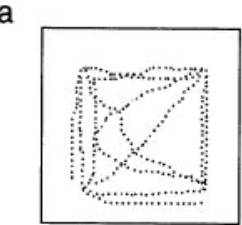

D

VT/P-TC

a b

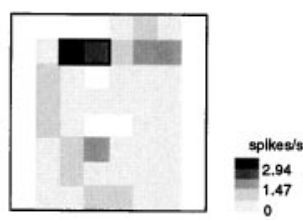

b

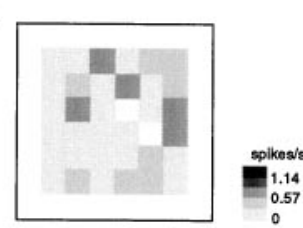

b
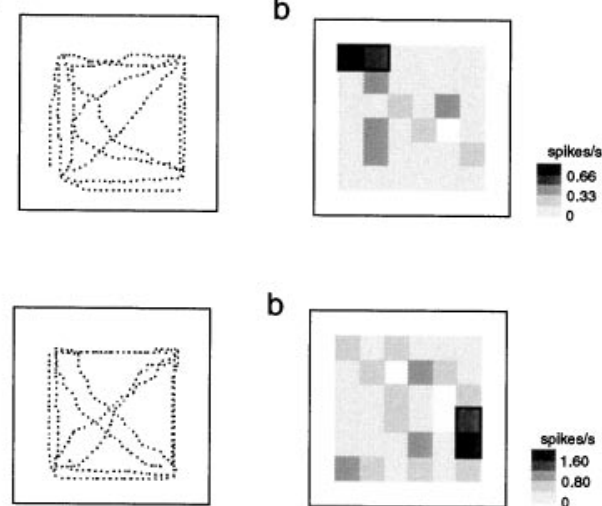

Trail map

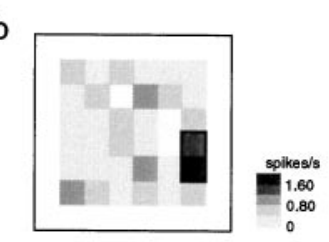

Firing rate map
A

B

C
RT/TC

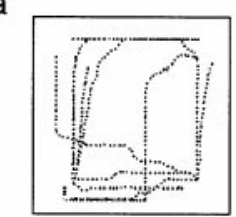

RT/P-TC

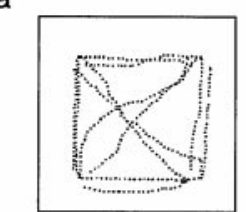

VT/P

b

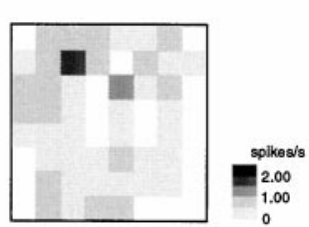

b

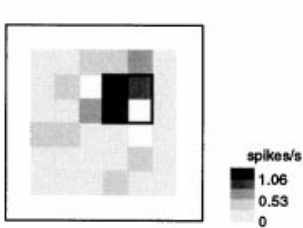

a

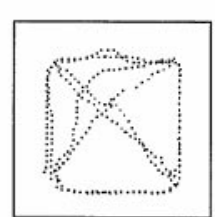

D

VT/P-TC

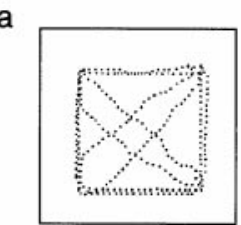

Trail map b

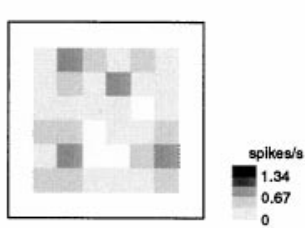

b

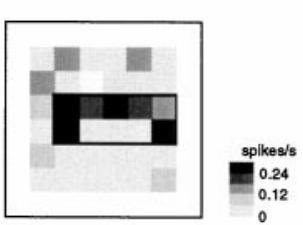

Firing rate map
Figure 8. An example of trail and firing rate maps of the RT/TCresponsive neurons that had place fields in the RT/TC, VT/P and VT/ P-TC tasks (RT/TC + VT/P + VT/P-TC in Table 1). Note that the HF neurons had partially overlapped place fields. In the RT/TC and VT/P tasks, the place fields in the left front area on the frame overlapped $(A b$, $\mathrm{Cb}$ ), but the place field was located around the right downward area on the window frame in the VT/P-TC task $(D b)$. Other descriptions as in Figure 3.

ANOVA; $\left.F_{(3,385)}=17.789 ; p<0.01\right)$. The post hoc test indicated that the grand mean firing rate of the nonresponsive neurons was significantly larger than those of the other three types of HF and PH neurons (Newman-Keuls test; $p<0.01$ ). This dichotomy of HF neurons with low and high mean firing rates corresponds to two types of HF neurons (pyramidal neurons and interneurons), as suggested by our previous study in monkeys (Eifuku et al., 1995) and other studies in rats (Fox and Rank, 1981; Kubie et al., 1990; Jung and McNaughton, 1993).

\section{Recording sites}

The recording sites of the various types of $\mathrm{HF}$ and $\mathrm{PH}$ neurons are shown in Figure 14. These recording sites are plotted on coronal sections of the left hemisphere. Most of the neurons were recorded from the CA1 and CA3 subfields, the dentate gyrus, and the $\mathrm{PH}$; some were recorded from the subiculum. Various types of location-differential neurons were widely distributed in various areas of the $\mathrm{HF}$ and $\mathrm{PH}$, and no significant segregation of specific neuronal types was observed.
Figure 9. An example of trail and firing rate maps of the HF neurons that had place fields in the RT/P-TC but not in the RT/TC tasks (Table 1, RT/P-TC-responsive without responses to RT/TC). Note that the HF neurons had completely overlapped place fields. There were overlapped place fields around the center of the frame in the RT/P-TC $(B b)$ and $\mathrm{VT} / \mathrm{P}-\mathrm{TC}(D b)$ tasks. Other descriptions as in Figure 3.

\section{DISCUSSION}

\section{Relationship between the neuron responses and characteristics of the four tasks}

In the RT/TC task, the pointer in the LCD monitor was not presented. Furthermore, the monkey always faced in the fixed direction, and consequently the same landmarks were seen in each trial. Therefore, the monkey had to judge its position based on the survey knowledge of the landmarks in the experimental room (i.e., relative spatial knowledge of place) (Thorndyke and Hayes-Roth, 1982; Aguirre and D'Esposito, 1997). Furthermore, the monkey could flexibly change its course during translocation when movement direction deviated from the destination. This evidence strongly suggests that the monkey's behavior was based on a cognitive map (locale system) in which the spatial relationships of various landmarks are represented, rather than taxon systems in which a set of stimulus (single landmark)-response (action or movement) associations are represented (O'Keefe and Nadel, 1978). On the other hand, the monkey did not necessarily judge its position based on the cognitive maps in the RT/P-TC task because its position was indicated by the pointer on the LCD monitor, although behavioral requirements in the RT/P-TC task 
A

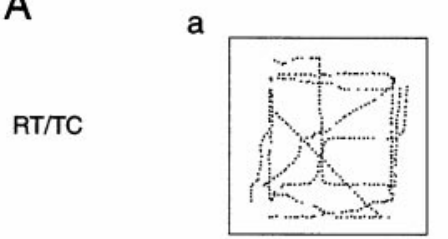

B

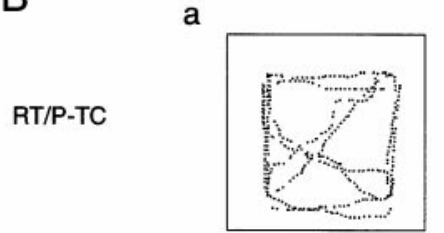

C VT/P

a

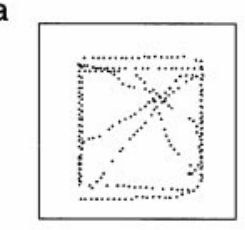

D

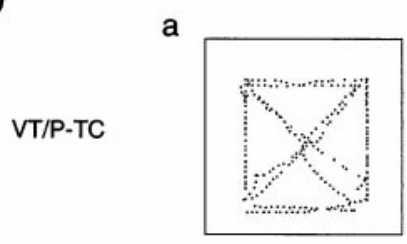

Trail map b

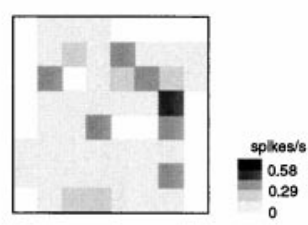

b

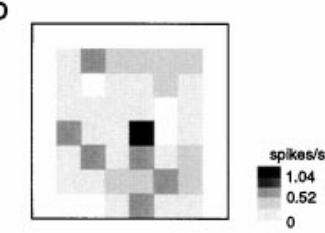

b

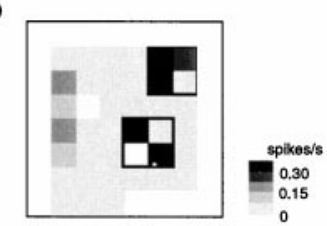

b

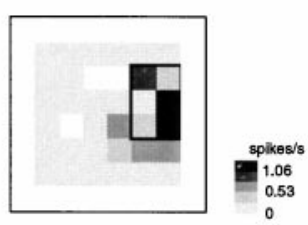

Firing rate map
A

$\mathrm{RT} / \mathrm{TC}$

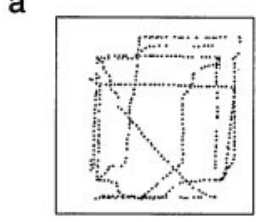

b

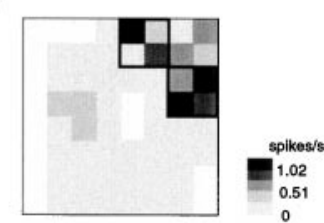

B

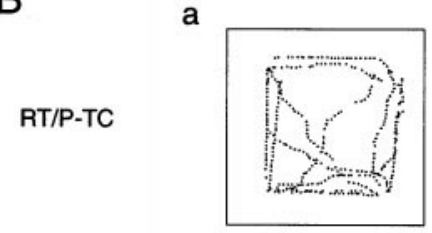

C

VT/P

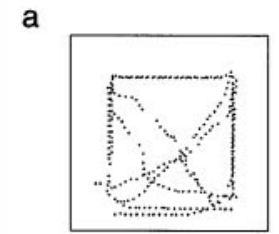

D

VT/P-TC

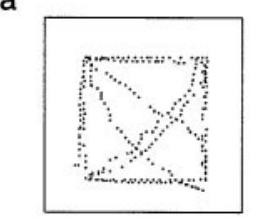

Trail map b

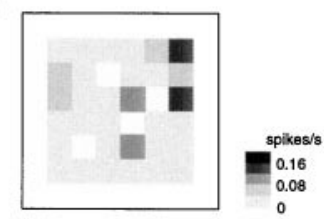

b

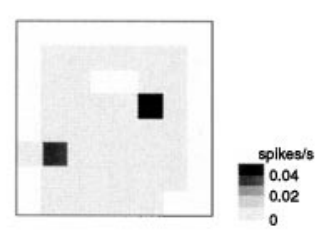

b

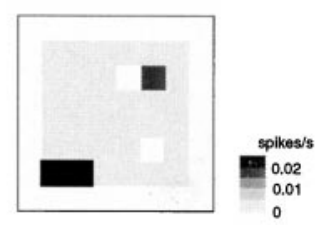

Firing rate map

Figure 10. An example of trail and firing rate maps of the HF neurons that had place fields only in the VT tasks (Table 1, Nonresponsive to RT). Note that the HF neuron had completely overlapped place fields in both the VT/P $(C b)$ and VT/P-TC $(D b)$ tasks. Other descriptions as in Figure 3.

were similar to those in the RT/TC tasks. The present results indicated that more $\mathrm{HF}$ and $\mathrm{PH}$ neurons responded in the $\mathrm{RT} / \mathrm{TC}$ than RT/P-TC tasks. This strongly suggests that the HF and PH are more important for the information processing in the locale system than in other systems and is consistent with the cognitive map theory advanced by O'Keefe and Nadel (1978) in which the HF was suggested to be a neural substrate of the cognitive map.

The VT tasks have similar characteristics to tabletop visuospatial tasks used in humans (e.g., Corsi Tapping task, ReyOsterrieth figure, stylus-maze learning, etc.). It has been reported that the patients with topographical disorientation seldom showed deficits in such tabletop tests (Habib and Sirigu, 1987; Maguire et al., 1996a). These clinical studies, along with the PET and fMRI studies, demonstrating an increase in blood flow in the $\mathrm{HF}$ and $\mathrm{PH}$ using a realistic virtual environment (see introductory remarks), suggest that it is important to test topographical disorientation with a real environment or a large-scale realistic virtual environment. In the present study, more HF neurons responded in the RT than in the VT tasks, which supports this idea. Furthermore, previous unit-recording studies of the monkey $\mathrm{HF}$ reported that approximately $10 \%$ (or $<10 \%$ ) of the $\mathrm{HF}$ neurons showed spatial responses when the monkey always re-

Figure 11. An example of trail and firing rate maps of the HF neurons that had place fields in the RT/TC and VT/P-TC tasks (Table 1, RT/TC $+\mathrm{VT} / \mathrm{P}-\mathrm{TC})$. Note that the HF neuron had nonoverlapped place fields. The HF neuron had two place fields in the right forward corner of the experimental field in the RT/TC task $(A b)$, whereas it had a place field in the left lower corner of the LCD monitor in the VT/P-TC task $(D b)$. Other descriptions as in Figure 3.

mained at a fixed location or when the monkey was moved by an experimenter passively (Cahusac et al., 1989; Miyashita et al., 1989; Rolls et al., 1989; Feigenbaum and Rolls, 1991). In the present study, $\sim 40 \%$ of the HF and PH neurons showed locationdifferential responses. These results indicate that population activity of $\mathrm{HF}$ and $\mathrm{PH}$ neurons is dependent on cognitive demands in allocentric spatial processing and are consistent with the recent fMRI study in humans in which the amount of neuronal activity is dependent on the computational demand that a given task imposes (Just et al., 1996). Together, this evidence strongly suggests a pivotal role of the $\mathrm{HF}$ and $\mathrm{PH}$ in allocentric spatial information processing in primates, as well as in rats.

\section{Place fields of the monkey HF and PH neurons}

The present study demonstrated that $30.6 \%$ of the primate HF and $\mathrm{PH}$ neurons had location-differential responses when the monkey performed the RT/TC task. These results are consistent with previous neurophysiological studies in rats (O'Keefe, 1976; McNaughton et al., 1983; Eichenbaum et al., 1987; Muller and Kubie, 1987; Wilson and McNaughton, 1993, 1994) and monkeys (Ono et al., 1991, 1993a,b; Nishijo et al., 1997). Previous neuro- 
A a. RT/TC

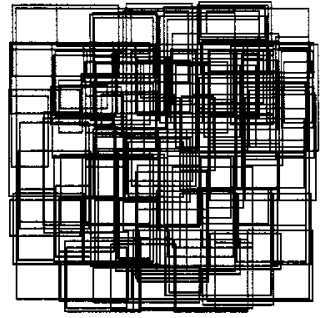

c. VT/P

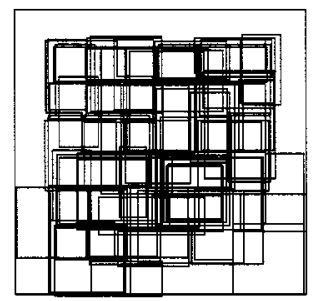

b. RT/P-TC

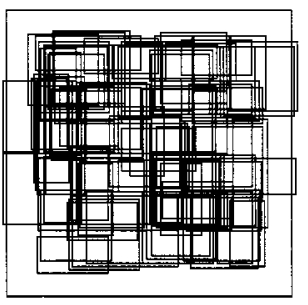

d. VT/P-TC

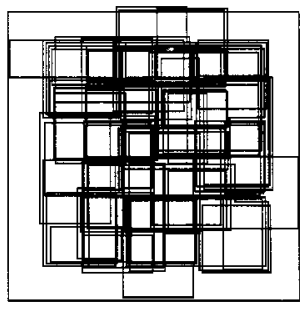

B

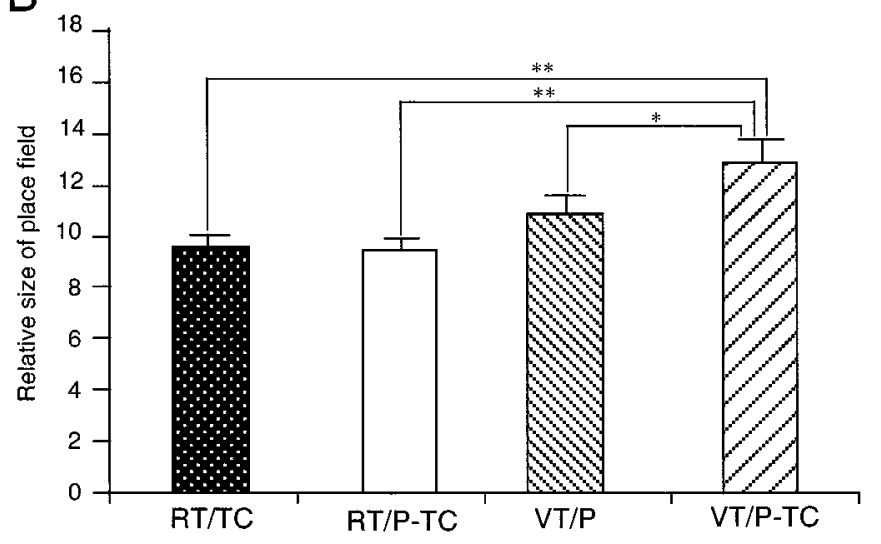

Figure 12. Locations and sizes of the place fields in the four different tasks. $A a-A d$, Locations and sizes of the HF and $\mathrm{PH}$ neurons that had place fields in the RT/TC $(n=119, A a), \mathrm{RT} / \mathrm{P}-\mathrm{TC}(n=73, A b), \mathrm{VT} / \mathrm{P}$ $(n=72, A c)$, and VT/P-TC $(n=66, A d)$ tasks. Note that place fields distributed randomly and covered most areas of the experimental field and the LCD monitor. $B$, Relative sizes of the place fields (see Materials and Methods for definition of the relative size of a place field). ${ }^{*} p<0.05$; ${ }^{* *} p<0.01$, significant difference from the mean relative size of the place field in the VT/P-TC task by Newman-Keuls test after one-way ANOVA $\left(F_{(3,326)}=5.654 ; p<0.01\right)$.

physiological studies in monkeys reported that the HF neurons responded to whole-body motion and view but not to place (O'Mara et al., 1994; Rolls and O’Mara, 1995). Because the cab moved at very slow speed (i.e., $3 \mathrm{~cm} / \mathrm{sec}$ ) with very slow acceleration (i.e., $4.5 \mathrm{~cm} / \mathrm{sec}^{2}$ ), which was comparable to or below the vestibular thresholds for humans (Young, 1984; Gianna et al., 1996), the HF neurons showing place fields in the RT tasks seemed not to respond to whole-body motion in the present study. Also, the HF and $\mathrm{PH}$ neurons consistently showed locationdifferential responses when the monkey went through the field with a different direction. This indicated that responses of the HF and $\mathrm{PH}$ neurons with the place fields were independent of specific views. These results strongly suggest that the $\mathrm{HF}$ and $\mathrm{PH}$ neurons with place fields correspond to place cells in rats. Previously, we reported that the responsiveness of the rodent place cells flexibly changed based on behavioral contexts and task demands and suggested that the HF neurons encoded preferentially relevant sensory information in a given context (Kobayashi et al., 1997). Therefore, the differences in neuronal responsiveness to place between the present and previous studies might be ascribed to differences in task demands between the present and previous studies.

In the present study, the mean relative sizes of the place fields in the RT/TC, RT/P-TC, and VT/P tasks were significantly smaller than that in the VT/P-TC task. It has been reported that sizes of place fields of the memory-impaired aged rats were larger than those of young and intact aged rats and that the sizes of the place fields became smaller with learning (Tanila et al., 1997). This suggests that the sizes of place fields are related to a degree of cognitive spatial information processing in the HF. Furthermore, place cell activity in rodents was reported to become faint during restraint of active locomotion (Foster et al., 1989). We also reported that, when the monkey was passively translocated, the place-related activity of most HF neurons turned out to be faint, suggesting that the primate HF represents space effectively in situations in which the animal actively interacts with space (Nishijo et al., 1997). Via interaction with space during spatial navigation, the animal must flexibly compare changing sensory inputs arising from locomotion with a stored representation of the environment (McNaughton et al., 1991; Knierim et al., 1995, 1996). This evidence suggests that the HF is crucial for active spatial information processing, which is a major cognitive demand during spatial navigation. In the present study, cognitive spatial processing was required at least in the VT/P-TC task because the pointer and target circle were continuously presented and the cab was located in the fixed places. Consistently, the place fields were most ambiguous in the VT/P-TC task. Together, these results strongly suggest that neuronal events in the HF are highly dependent on cognitive demands required for spatial tasks and the animal's active interaction with the environment.

\section{Activity of the HF and PH neurons across the tasks}

Most HF and $\mathrm{PH}$ neurons (89.2\%) had nonoverlapped place fields rather than overlapped place fields in the present study. It has been reported that activity of the rodent place cells in the CA1 and CA3 subfields was highly sensitive to environmental changes and showed different representation in each different environment (for review, see Redish and Touretzky, 1997). These results in rodent place cells were consistent with the present results in which different neuronal representations were established in different tasks.

Recent theoretical studies proposed that the HF represented the external world by a reference frame (Redish and Touretzky, 1997) or chart (Samsonovich and McNaughton, 1997) system in which different assemblies of different HF neurons or HF neurons with different place fields were created in different environments or behavioral contexts. The four different maps of the place fields in the four different tasks shown in Figure $12 \mathrm{~A}$ might correspond to four different reference frames or charts. Recent neurophysiological and behavioral studies support this idea that the HF is important in the creation of reference frames and consequently in reducing interference among different environments and contexts. Place fields of the place cells of aged rats with spatial memory deficits were unstable when tested repeatedly in a same environment, suggesting that those animals have deficits in se- 
A

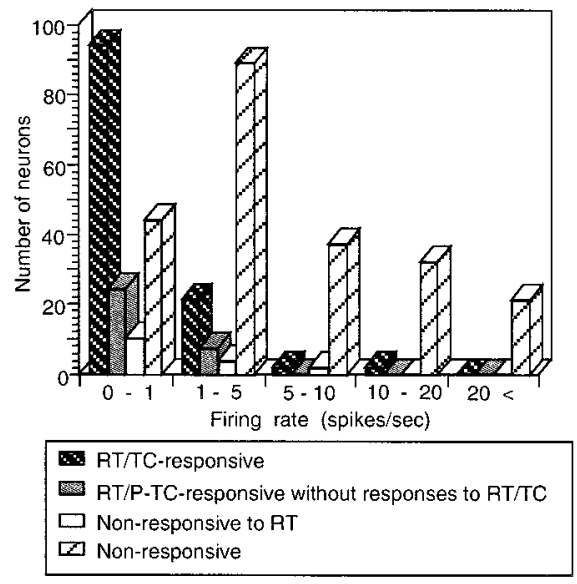

B

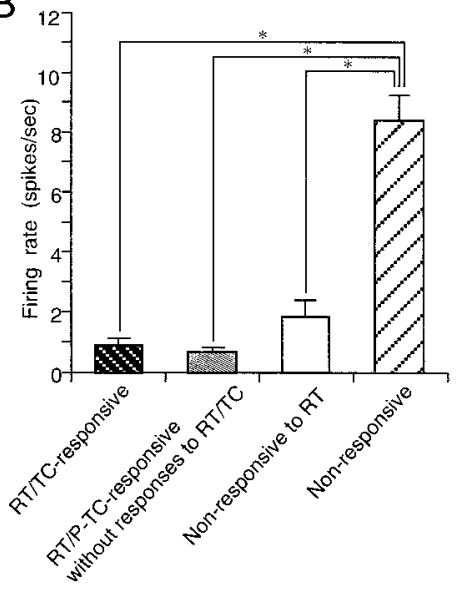

Figure 13. Comparison of spontaneous firing rates among the four types of the HF and PH neurons. $A$, Distributions of spontaneous firing rates of the three types of location-differential and nonresponsive neurons in Table 1. Note that most location-differential neurons had low spontaneous firing rates of $<5$ spike/sec, whereas mean spontaneous firing rates of the nonresponsive neurons distributed widely from low to high spontaneous firing rates. $B$, Comparison of mean spontaneous firing rates of the four types of the HF neurons. ${ }^{*} p<0.01$, significant difference from the mean spontaneous firing rate of the nonresponsive neurons by Newman-Keuls test after one-way ANOVA $\left(F_{(3,385)}=\right.$ $17.789 ; p<0.01)$.
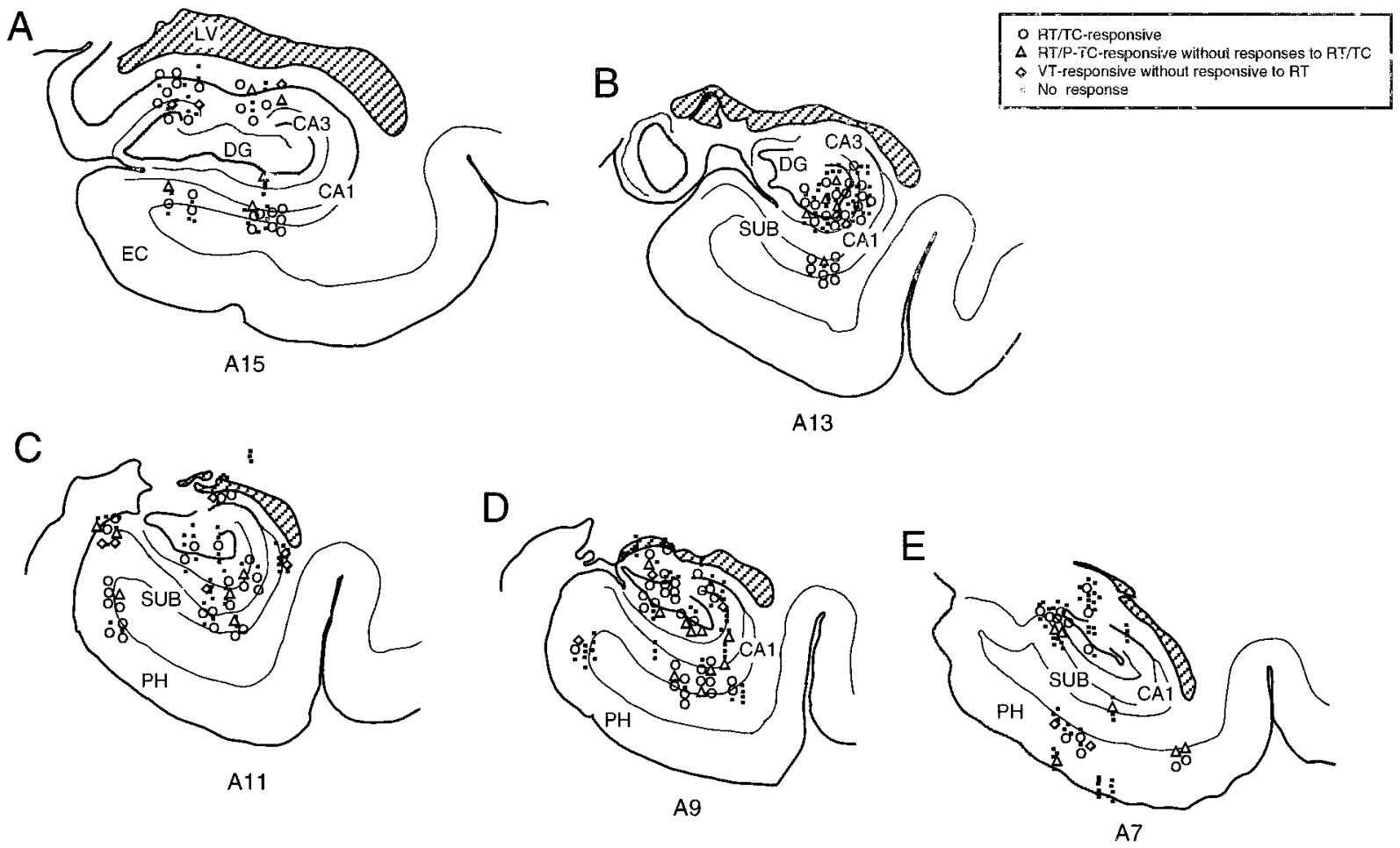

Figure 14. Recording sites of various neuron types in monkey HF and PH. Numbers below each section indicate distance (in millimeters) from interaural line. Most of the HF neurons were recorded from the $C A 1$ and $C A 3$ subfields, the dentate gyrus $(D G)$, and the $P H$; some were recorded from the subiculum $(S U B)$. Note that various types of location-differential neurons distributed widely in various areas of the $\mathrm{HF}$ and $\mathrm{PH}$, and no significant segregation of specific types of neurons was observed. $L V$, Lateral ventricle.

lecting a correct reference frame in a familiar environment (Barnes et al., 1997). Rats with HF lesions exhibited the same behavioral responses to contextual cues, regardless of the degree of conditioning (Winocur et al., 1987), and humans and animals with HF damages were impaired when acquiring conditional relationship between stimuli in a variety of situations (Hirsh, 1980; Ross et al., 1984). All of this evidence suggests that an assembly of reference frames is a neural basis of episodic memory for various events that occurred in different environmental and contextual situations.

However, $10.2 \%$ of the location-differential neurons did have overlapped place fields across the tasks in the present study. We speculate that the monkey might accept the LCD monitor as a map of a real space because the four tasks used in the present study had similar characteristics. These HF and PH neurons with overlapped place fields might function to connect the four different reference frames, among which there were significant pointto-point relationships. Future computational studies may clarify and test this hypothesis.

\section{REFERENCES}

Abrahams S, Pickering A, Polkey CE, Morris RG (1997) Spatial memory deficits in patients with unilateral damage to the right hippocampal formation. Neuropsychologia 35:11-24.

Aguirre GK, D'Esposito M (1997) Environmental knowledge is subserved by separable dorsal/ventral neural areas. J Neurosci $17: 2512-2518$. 
Aguirre GK, Detre JA, Alsop DC, D'Esposito M (1996) The parahippocampus subserves topographical learning in man. Cereb Cortex 6:823-829.

Barnes CA, Suster MS, Shen J, McNaughton BL (1997) Multistability of cognitive maps in the hippocampus of old rats. Nature 388:272-275.

Breese CR, Hampson RE, Deadwyler SA (1989) Hippocampal place cells: stereotypy and plasticity. J Neurosci 9:1097-1111.

Cahusac PMB, Miyashita Y, Rolls ET (1989) Responses of hippocampal formation neurons in the monkey related to delayed spatial response and object-place memory tasks. Behav Brain Res 33:229-240.

Eichenbaum H, Kuperstein M, Fagan A, Nagode J (1987) Cue-sampling and goal-approach correlates of hippocampal unit activity in rats performing an odor-discrimination task. J Neurosci 7:716-732.

Eifuku S, Nishijo H, Kita T, Ono T (1995) Neuronal activity in the primate hippocampal formation during a conditional association task based on the subject's location. J Neurosci 15:4952-4969.

Feigenbaum JD, Rolls ET (1991) Allocentric and egocentric spatial information processing in the hippocampal formation of the behaving primate. Psychobiology 19:21-41.

Foster TC, Castro CA, McNaughton BL (1989) Spatial selectivity of rat hippocampal neurons: dependence on preparedness for movement. Science 244:1580-1582.

Ghaem O, Mellet E, Crivello F, Tzourio N, Mazoyer B, Berthoz A, Denis M (1997) Mental navigation along memorized routes activates the hippocampus, precuneus, and insula. NeuroReport 8:739-744.

Gianna C, Heimbrand S, Gresty M (1996) Thresholds for detection of motion direction during passive lateral whole-body acceleration in normal subjects and patients with bilateral loss of labyrinthine. Brain Res Bull 40:443-449.

Habib M, Sirigu A (1987) Pure topographical disorientation: a definition and anatomical basis. Cortex 23:73-85.

Hirsh R (1980) The hippocampus, conditional operations, and cognition. Physiol Psychol 8:175-182.

Jung MW, McNaughton BL (1993) Spatial selectivity of unit activity in the hippocampal granular layer. Hippocampus 3:165-182.

Just MA, Carpenter PA, Keller TA, Eddy WF, Thulborn KR (1996) Brain activation modulated by sentence comprehension. Science 274:114-116.

Knierim JJ, Kudrimoti HS, McNaughton BL (1995) Place cells, head direction cells, and the learning of landmark stability. J Neurosci 15:1648-1659.

Knierim JJ, Kudrimoti HS, Skaggs WE, McNaughton BL (1996) The interaction between vestibular cues and visual landmark learning in spatial navigation. In: Perception, memory, and emotion: frontiers in neuroscience (Ono T, ed), pp 343-357. Oxford: Elsevier.

Kobayashi T, Nishijo H, Fukuda M, Bures J, Ono T (1997) Taskdependent representations in rat hippocampal place neurons. J Neurophysiol 78:597-613.

Kusama T, Mabuchi M (1970) Stereotaxic atlas of the brain of Macaca fuscata. Tokyo: Tokyo UP.

Maguire EA, Burke T, Phillips J, Staunton H (1996a) Topographical disorientation following unilateral temporal lobe lesions in humans. Neuropsychologia 34:993-1001.

Maguire EA, Frackowiak RSJ, Frith CD (1996b) Learning to find your way: a role for the human hippocampal formation. Proc R Soc Lond B Biol Sci 263:1745-1750.

Maguire EA, Frackowiak RSJ, Frith CD (1997) Recalling routes around London: activation of the right hippocampus in taxi drivers. J Neurosci 15:7103-7110.

McNaughton BL, Barnes CA, O'Keefe J (1983) The contribution of position, direction, and velocity to single unit activity in the hippocampus of freely-moving rats. Exp Brain Res 52:41-49.

McNaughton BL, Chen LL, Markus EJ (1991) "Dead reckoning," landmark learning, and the sense of direction: a neurophysiological and computational hypothesis. J Cognit Neurosci 3:190-202.

Miyashita Y, Rolls ET, Cahusac PMB, Niki H, Feigenbaum JD (1989) Activity of hippocampal formation neurons in the monkey related to a conditional spatial response task. J Neurophysiol 61:669-678.
Muller RU, Kubie JL (1987) The effects of changes in the environment on the spatial firing of hippocampal complex-spike cells. J Neurosci 7:1951-1968.

Nishijo H, Ono T, Tamura R, Nakamura K (1993) Amygdalar and hippocampal neuron responses related to recognition and memory in monkey. Prog Brain Res 95:339-357.

Nishijo H, Ono T, Eifuku S, Tamura R (1997) The relationship between monkey hippocampus place-related neural activity and action in space. Neurosci Lett 226:57-60.

O'Keefe J (1976) Place units in the hippocampus of the freely moving rat. Exp Neurol 51:78-109.

O’Keefe J, Dostrovsky J (1971) The hippocampus as a spatial map. Preliminary evidence from unit activity in the freely-moving rat. Brain Res 34:171-175.

O'Keefe J, Nadel L (1978) The hippocampus as a cognitive map. Oxford: Clarendon.

O'Keefe J, Speakman A (1987) Single unit activity in the rat hippocampus during a spatial memory task. Exp Brain Res 68:1-27.

Olton DS, Branch M, Best PJ (1978) Spatial correlates of hippocampal unit activity. Exp Neurol 58:387-409.

O'Mara SM, Rolls ET, Berthoz A, Kesner RP (1994) Neurons responding to whole-body motion in the primate hippocampus. J Neurosci 14:6511-6523.

Ono T, Nakamura K, Fukuda M, Tamura R (1991) Place recognition responses of neurons in monkey hippocampus. Neurosci Lett 121:194-198.

Ono T, Eifuku S, Nakamura K, Nishijo H (1993a) Monkey hippocampal neuron responses related to spatial and non-spatial influence. Neurosci Lett 159:75-78.

Ono T, Nakamura K, Nishijo H, Eifuku S (1993b) Monkey hippocampal neuron related to spatial and non spatial functions. J Neurophysiol 70:1516-1529.

Redish AD, Touretzky DS (1997) Cognitive maps beyond the hippocampus. Hippocampus 7:15-35.

Rolls ET, O'Mara SM (1995) View-responsive neurons in the primate hippocampal complex. Hippocampus 5:409-424.

Rolls ET, Miyashita Y, Cahusac PMB, Kesner RP, Niki H, Feigenbaum JD, Bach L (1989) Hippocampal neurons in the monkey with activity related to the place in which a stimulus is shown. J Neurosci 9:1835-1845.

Ross RT, Orr WB, Holland PC, Berger TW (1984) Hippocampectomy disrupts acquisition and retention of learned conditioned responding. Behav Neurosci 98:211-225.

Samsonovich A, McNaughton BL (1997) Path integration and cognitive mapping in a continuous attractor neural network model. J Neurosci 17:5900-5920.

Suzuki WA, Miller EK, Desimone R (1997) Object and place memory in the macaque entorhinal cortex. J Neurophysiol 78:1062-1081.

Tanila H, Shapiro M, Gallagher M, Eichenbaum H (1997) Brain aging: changes in the nature of information coding by the hippocampus. J Neurosci 17:5155-5166.

Thompson LT, Best PJ (1990) Long-term stability of the place-field activity of single units recorded from the dorsal hippocampus of freely behaving rats. Brain Res 509:299-308.

Thorndyke PW, Hayes-Roth B (1982) Difference in spatial knowledge acquired from maps and navigation. Cognit Psychol 14:560-589.

Watanabe T, Niki H (1985) Hippocampal unit activity and delayed response in the monkey. Brain Res 325:241-254.

Wilson MA, McNaughton BL (1993) Dynamics of the hippocampal ensemble code for space. Science 261:1055-1058.

Wilson MA, McNaughton BL (1994) Reactivation of hippocampal ensemble memories during sleep. Science 265:676-679.

Winocur G, Rawlins JNP, Gray JA (1987) The hippocampus and conditioning to contextual cues. Behav Neurosci 101:617-625.

Young L (1984) Perception of the body in space. In: Handbook of physiology, Vol 14, Sensory processes. Bethesda, MD: American Physiological Society. 